\title{
Lens dislocation has a possible relationship with laser iridotomy
}

This article was published in the following Dove Press journal:

Clinical Ophthalmology

4 December 2012

Number of times this article has been viewed

\author{
Tetsuya Mutoh ${ }^{1,2}$ \\ Kevin F Barrette ${ }^{2}$ \\ Yukihiro Matsumoto' \\ Makoto Chikuda' \\ 'Department of Ophthalmology, \\ Dokkyo Medical University Koshigaya \\ Hospital, Koshigaya City, Saitama, \\ Japan; '2Department of Ophthalmology, \\ Boston University School of Medicine, \\ Boston, MA, USA
}

\begin{abstract}
We report our recent experience of four eyes with spontaneous lens dislocation in four patients with no history of trauma or any systemic disease associated with zonular dialysis. Lens dislocation developed with 0.5 to 6 months following laser iridotomy. All patients were male and two eyes were complicated with acute primary angle closure glaucoma preoperatively. Case 1 showed bilateral lens dislocation, while cases 2 and 3 involved unilateral lens dislocation. Cases 2 and 3 showed lenses completely dislocated into the vitreous cavity. All cases needed lens removal and scleral fixation of intraocular lenses. Final visual acuity was 1.2 in all cases. We suspect that laser iridotomy may induce localized zonular dialysis that results in progressive zonular weakness, leading to lens dislocation.
\end{abstract}

Keywords: lens dislocation, laser iridotomy, primary angle closure glaucoma

\section{Introduction}

Laser iridotomy or surgical peripheral iridectomy is typically performed after eye administration and intravenous drip injection of anti-glaucomatous drugs as a primary treatment for acute primary angle closure glaucoma. ${ }^{1,2}$ Laser iridotomy is performed not only for treatment of acute primary angle closure glaucoma, but also for prevention of this condition. ${ }^{3}$ Cases of complete dislocation of the lens into the vitreous cavity $^{4,5}$ or dislocation of the lens into the anterior chamber ${ }^{3,6-8}$ have been reported after laser iridotomy. ${ }^{9,10}$ Causes of lens dislocation include trauma, Marfan syndrome, pseudoexfoliation syndrome, retinitis pigmentosa, homocysteinuria, uveitis, and microspherophakia. ${ }^{4,5,11-13}$ We encountered three cases of lens dislocation after laser iridotomy in four eyes from patients with no personal or family history of these conditions.

\section{Case report I}

A 68-year-old man presented with lens dislocation in the right eye. The patient had undergone laser iridotomy in both eyes at his former clinic 2 months prior to our examination due to acute primary angle closure glaucoma in the right eye. Best corrected visual acuity (BCVA) in the right eye was $0.6(+0.50$ diopters [D]) and in the left eye was $0.8(+1.00,-2.00 \times 170)$. Intraocular pressure was $29 \mathrm{mmHg}$ in the right eye and $19 \mathrm{mmHg}$ in the left eye. Gonioscopy showed narrow angles in both eyes. Corneal endothelial cell density in the right eye was 2890 cells $/ \mathrm{mm}^{2}$ and in the left eye was 2755 cells $/ \mathrm{mm}^{2}$. There was no history or any sign of ocular or systemic abnormality associated with lens dislocation, eg, eye trauma, pseudoexfoliation, Marfan syndrome, retinitis pigmentosa, homocysteinuria, or uveitis. On slit-lamp examination, the lens
Correspondence: Tetsuya Mutoh Department of Ophthalmology, Dokkyo Medical University Koshigaya Hospital, 2-I-50 Minami-koshiagya, Koshigaya City, Saitama 343-8555, Japan

Tel +8I48965 I I I I

$\mathrm{Fax}+8 \mid 48965$ II 27

Email mtetsuya@dokkyomed.ac.jp 
was dislocated posteriorly in the right eye and laser iridotomy was open in both eyes (Figures 1 and 2). Anterior vitrectomy, lens removal, and scleral fixation of an intraocular lens (P366UV, Bausch and Lomb, +18.0 D) were performed immediately in the right eye.

Six months after laser iridotomy, the patient experienced sudden visual loss in the left eye. BCVA in the right eye was $1.2(+0.50,2.00 \times 180)$ and in the left eye was $0.3(-2.00$, $0.50 \times 70)$. Intraocular pressure in the right eye was $14 \mathrm{mmHg}$ and in the left eye was $19 \mathrm{mmHg}$. Corneal endothelial cell density in the right eye was 2732 cells $/ \mathrm{mm}^{2}$ and in the left eye was 2695 cells $/ \mathrm{mm}^{2}$. Upon slit-lamp examination, the lens was dislocated into the anterior chamber in the left eye (Figure 3). Anterior vitrectomy, lens removal, and scleral fixation of an intraocular lens (VA-65BB, HOYA, $+18.5 \mathrm{D})$ were performed immediately. Twenty-eight months after bilateral laser iridotomy, the BCVA was $1.0(-0.75$, $-0.75 \times 120$ ) and intraocular pressure was $16 \mathrm{mmHg}$ in the left eye. Corneal endothelial cell density in the right eye was 2667 cells $/ \mathrm{mm}^{2}$ and in the left eye was 792 cells $/ \mathrm{mm}^{2}$.

\section{Case report 2}

A 52-year-old Japanese man presented with acute primary angle closure glaucoma in the right eye. On examination, BCVA in the right eye was $1.0(-0.25,-3.00 \times 90)$ and was $1.2(-0.50)$ in the left eye. Intraocular pressure was $16 \mathrm{mmHg}$ in both eyes. Gonioscopic examination showed complete closure over 360 degrees in both eyes. Primary angle closure glaucoma was diagnosed, and multicolor laser iridotomy was performed in the right eye on the same day. Seven days later, the same procedure was performed in the left eye.

Four months after laser iridotomy, the patient complained of acute decreased vision in the right eye without any recent history

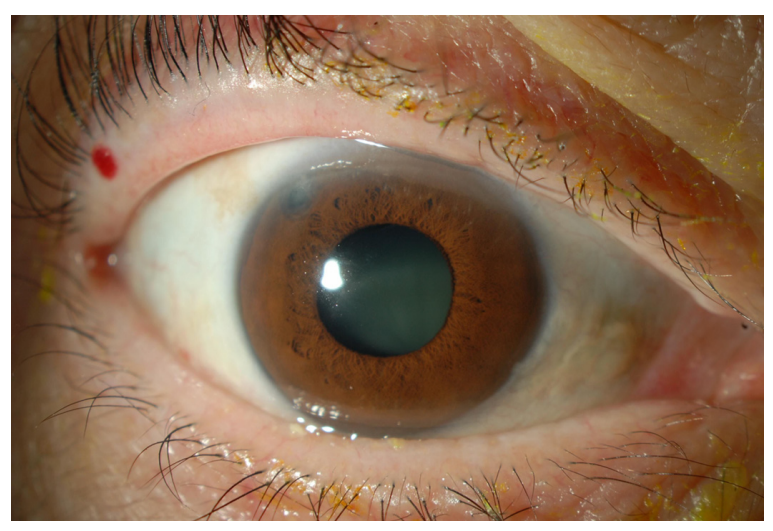

Figure I Anterior segment of right eye at initial visit in case I.

Notes: Crystalline lens was dislocated into the posterior chamber. Laser iridotomy was open at 10 o'clock.

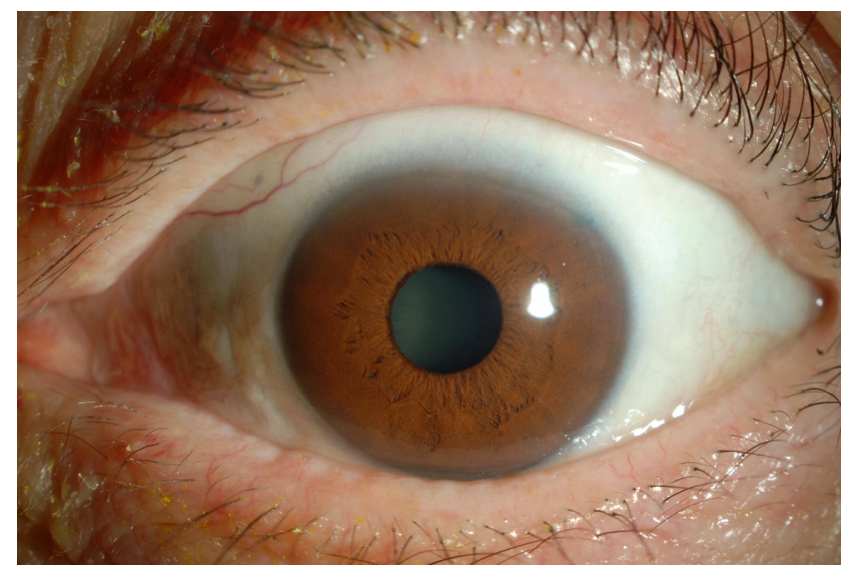

Figure 2 Anterior segment of the left eye at initial visit in case 1.

Note: Crystalline lens was in the normal position and laser iridotomy was open at 2 o'clock.

of eye trauma. BCVA was $1.0(+15.5,+0.75 \times 95)$ and corneal central endothelial cell density was 2342 cells $/ \mathrm{mm}^{2}$ on specular microscopy. No crystalline lens was present on slit-lamp examination. Following mydriatic examination, lens displacement into the vitreous cavity was seen (Figure 4). A 25-gauge pars plana vitrectomy, lens removal, and scleral fixation of an intraocular lens (P366UV, Bausch and Lomb, +25.0 D) were performed immediately in the right eye. Nine months after laser iridotomy, BCVA was $1.2(+2.25,-2.50 \times 100)$ and intraocular pressure was $16 \mathrm{mmHg}$ in the right eye.

\section{Case report 3}

A 71-year-old Japanese man presented to the emergency room complaining of a "feeling of wrongness" in the right eye. The patient had undergone laser iridotomy in both eyes at his former clinic 2 weeks prior to our consultation due to acute primary angle closure glaucoma in the right eye.

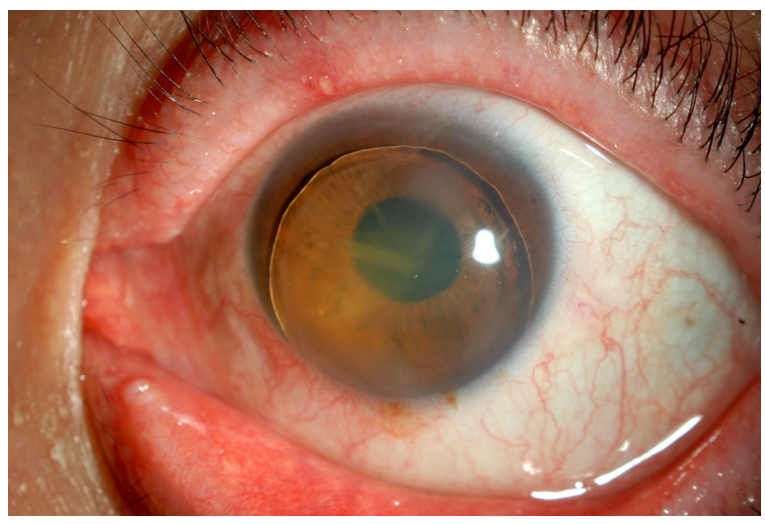

Figure 3 Preoperative anterior segment of the left eye in case I.

Notes: Crystalline lens was in the anterior chamber completely. Laser iridotomy can be seen at 2 o'clock slightly. 


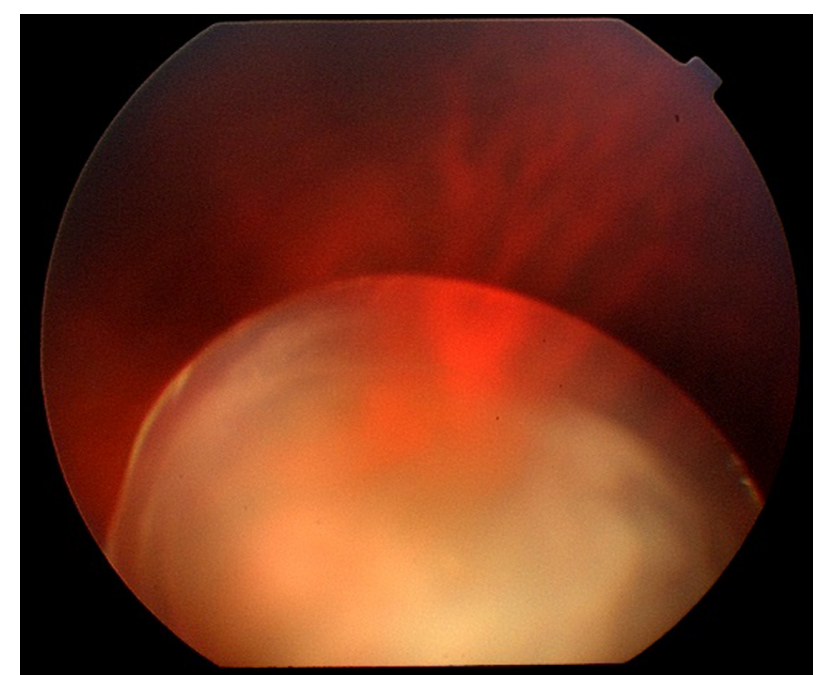

Figure 4 Preoperative ocular fundus examination of the right eye in case 2. Note: The lens has been displaced into the vitreous cavity.

Intraocular pressure was $28 \mathrm{mmHg}$ in the right eye and laser iridotomies were open in both eyes. The patient was continuing the ophthalmic solutions and drugs prescribed for internal use at his former clinic.

Four weeks after laser iridotomy, the patient complained of acute decreased vision in the right eye without any recent history of eye trauma. On examination, BCVA in the right eye was $1.0(+11.0,+0.50 \times 35)$ and in the left eye was 1.2 (non corrigent). Intraocular pressure in the right eye was $16 \mathrm{mmHg}$ and in the left eye was $13 \mathrm{mmHg}$. Gonioscopy showed narrow angles in both eyes. Corneal endothelial cell density in the right eye was 2833 cells $/ \mathrm{mm}^{2}$ and was 2740 cells/ $\mathrm{mm}^{2}$ in the left eye. There was no history or sign of any ocular or systemic abnormality known to be associated with lens dislocation. On slit-lamp examination, no crystalline lens was present. Lens displacement into the vitreous cavity was seen on mydriatic examination. A 25-gauge pars plana vitrectomy, lens removal, and scleral fixation of an intraocular lens (VA-65BB, HOYA, 25.0 D) were performed immediately in the right eye. Four years after laser iridotomy, BCVA was $1.2(+0.50)$ and intraocular pressure was $13 \mathrm{mmHg}$ in the right eye. Corneal endothelial cell density in the right eye was 2688 cells $/ \mathrm{mm}^{2}$.

\section{Discussion}

A summary of all cases is shown in Table 1. The laser iridotomy conditions for Case 2 are detailed in Table 2. To the best of our knowledge, only two cases demonstrating complete dislocation of lenses into the vitereous cavity after laser iridotomy have been reported till now. One by Seo et $\mathrm{al}^{4}$ and another reported by Moore et al. ${ }^{5}$ Cases 2 and 3 in the current report showed complete lens dislocation into the vitreous cavity after laser iridotomy. The cases reported by Seo et al were unknown complicated acute primary angle closure glaucoma or prevention for acute primary angle closure glaucoma and other diseases including eye trauma. ${ }^{4}$ Although improved surgical results and a decreased number of complications are due to development of techniques and instruments in vitreoretinal surgery, it is unwise to offer unnecessary intervention. Some cases have developed retinal detachment as a complication after surgery. ${ }^{11}$

Seong et al, ${ }^{3}$ Melamed et al, ${ }^{6}$ Kawashima et al, ${ }^{7}$ and Kwon et $a l^{8}$ have reported lenses dislocated into the anterior chamber after laser iridotomy. The left eye of case 1 in the current report was the fifth known report in which a lens was completely dislocated into the vitreous cavity after laser iridotomy. Case 1 was the second bilateral case after that reported by Kwon et al, ${ }^{8}$ which showed bilaterally dislocated lenses after laser iridotomy.

Past reports involving a total of seven eyes included three with acute primary angle closure glaucoma, ${ }^{5,6,8}$ one with pseudoexfoliation syndrome, ${ }^{6}$ one with eye trauma, ${ }^{6}$ one with retinitis pigmentosa ${ }^{8}$ and one with phacodonesis ${ }^{8}$ as the complication before laser iridotomy. ${ }^{3,5-8}$

To the best of our knowledge, no reports have been documented in which only acute primary angle closure glaucoma caused lens dislocation. There is a strong connection between acute primary angle closure glaucoma and weakness of the ciliary zonule. ${ }^{1,14}$ There is no consensus as yet whether zonular instability is a consequence of acute primary angle closure glaucoma or if zonular instability causes acute primary angle closure glaucoma. ${ }^{1}$ Laser iridotomy with high energy and carelessly focused shots might

Table I Summary of three cases (four eyes)

\begin{tabular}{|c|c|c|c|c|c|c|c|}
\hline Number & $\begin{array}{l}\text { Eyelage (years)/ } \\
\text { gender }\end{array}$ & $\begin{array}{l}\text { Time from LI to } \\
\text { lens dislocation }\end{array}$ & $\begin{array}{l}\text { Complicated } \\
\text { acute PACG }\end{array}$ & Pre-VA & $\begin{array}{l}\text { Pre-CECD } \\
\left(\text { cells } / \mathrm{mm}^{2}\right)\end{array}$ & Post-VA & $\begin{array}{l}\text { Post-CECD } \\
\left(\text { cells } / \mathrm{mm}^{2}\right)\end{array}$ \\
\hline \multirow[t]{2}{*}{ I } & $\mathrm{R} / 68 / \mathrm{M}$ & $2 M$ & + & 0.6 & 2890 & 1.2 & 2667 \\
\hline & $\mathrm{L} / 68 / \mathrm{M}$ & $6 M$ & - & 0.3 & 2695 & 1.2 & 792 \\
\hline 2 & $\mathrm{R} / 52 / \mathrm{M}$ & $4 M$ & - & 1.2 & 2342 & 1.2 & Unknown \\
\hline 3 & $\mathrm{R} / 7 \mathrm{I} / \mathrm{M}$ & $0.5 \mathrm{M}$ & + & 1.2 & 2833 & 1.2 & 2688 \\
\hline
\end{tabular}

Abbreviations: LI, laser iridotomy; PACG, primary angle closure glaucoma; Pre-VA, preoperative visual acuity; Pre-CECD, preoperative corneal endothelial cell density; Post-VA, postoperative visual acuity; Post-CECD, postoperative corneal endothelial cell density; M, months. 
Table 2 Laser condition of case 2

\begin{tabular}{llll}
\hline Eyes & Type of laser & Energy $(\mathbf{m W})$ & Shots $(\mathbf{n})$ \\
\hline First step & Muliticolor yellow & 200 & 10 \\
$\begin{array}{l}\text { Right, left } \\
\text { Second step }\end{array}$ & Muliticolor red & 900 & 1000 \\
Right & Muliticolor red & 900 & 321 \\
Left &
\end{tabular}

Abbreviation: $\mathrm{mW}$, milliwatt.

induce zonular rupture. Above all, laser iridotomy performed for acute primary angle closure glaucoma without complication may cause lens dislocation. In addition, phacodonesis, retinitis pigmentosa, pseudoexfoliation syndrome, and a past history of eye trauma will increase the risk of lens dislocation. Primary phacoemulsification and aspiration and intraocular lens implantation for acute primary angle closure glaucoma without complication have increased in the last 10 years. ${ }^{1,15}$ Because the results were good, ${ }^{1,15}$ we will be able to decrease laser iridotomy in the future. None of our three patients pursued a lawsuit because the results were good, but laser iridotomy with careless diagnosis may induce lens dislocation. Although the complication rate is low, ${ }^{2}$ we must consider the safety of laser iridotomy.

\section{Disclosure}

The authors report no conflicts of interest in this work.

\section{References}

1. Nishino K, Yoshida F, Saitoh M, et al. Primary phacoemulsification and aspiration and intraocular lens implantation for acute primary angleclosure glaucoma. Journal of the Eye. 2009;26:689-694.
2. Liu DT, Lai JS, Lam DS. Descemet membrane detachment after sequential argon-neodymium: YAG laser peripheral iridotomy. $\mathrm{Am} J$ Ophthalmol. 2002;134:621-622.

3. Seong M, Kim MJ, Tchah H. Argon laser iridotomy as a possible cause of anterior dislocation of a crystalline lens. J Cataract Refract Surg. 2009;35:190-192.

4. Seo MS, Yoon KC, Lee CH. Phacofragmentation for the treatment of a completely posterior dislocation of the total crystalline lens. Korean J Ophthalmol. 2002;16:32-36.

5. Moore SP, Smith M, Rattigan S, Gray R. Lens dislocation following YAG laser peripheral iridotomy. Ophthalmic Surg Lasers Imaging. 2010;9:1-2.

6. Melamed S, Barraquer E, Epstein DL. Neodymium:YAG laser iridotomy as a possible contribution to lens dislocation. Ann Ophthalmol. 1986;18: 281-282.

7. Kawashima M, Kawakita T, Shimazaki J. Complete spontaneous crystalline lens dislocation into the anterior chamber with severe corneal endothelial cell loss. Cornea. 2007;26:487-489.

8. Kwon YA, Bae SH, Sohn YH. Bilateral spontaneous anterior lens dislocation in a retinitis pigmentosa patient. Korean JOphthalmol. 2007;21: 124-126.

9. Mackool RJ. Argon laser iridotomy and crystalline lens dislocation. $J$ Cataract Refract Surg. 2009;35:1323.

10. Kumar V, Ghosh B, Goel N. Argon laser iridotomy as a possible cause of anterior dislocation of a crystalline lens. J Cataract Refract Surg. 2009;35:1324.

11. Oh J, Smiddy WE. Pars plana lensectomy combined with pars plana vitrectomy for dislocated cataract. $J$ Cataract Refract Surg. 2010;36: 1189-1194.

12. Sato H, Wada $Y$, Abe T, et al. Retinitis pigmentosa associated with ectopia lentis. Arch Ophthalmol. 2002;120:852-854.

13. Verloes A, Hermia JP, Galand A, Koulischer L, Dodinval P. Glaucoma-lens ectopia-microspherophakia-stiffness-shortness (GEMSS) syndrome: a dominant disease with manifestations of Weill-Marchesani syndromes. Am J Med Genet. 1992;44:48-51.

14. Hwang YH, Kim YY, Kirti K, Rho B. Capsule wrinkling during capsulorhexis in patients with primary angle-closure glaucoma and cataract. Jpn J Ophthalmol. 2010;54:401-406.

15. Jacobi PC, Dietlein TS, Lüke C, Engels B, Krieglstein GK. Primary phacoemulsification and aspiration and intraocular lens implantation for acute angle-closure glaucoma. Ophthalmology. 2002;109:1597-1603.
Clinical Ophthalmology

\section{Publish your work in this journal}

Clinical Ophthalmology is an international, peer-reviewed journal covering all subspecialties within ophthalmology. Key topics include: Optometry; Visual science; Pharmacology and drug therapy in eye diseases; Basic Sciences; Primary and Secondary eye care; Patient Safety and Quality of Care Improvements. This journal is indexed on Submit your manuscript here: http://www.dovepress.com/clinical-ophthalmology-journal

\section{Dovepress}

PubMed Central and CAS, and is the official journal of The Society of Clinical Ophthalmology (SCO). The manuscript management system is completely online and includes a very quick and fair peer-review system, which is all easy to use. Visit http://www.dovepress.com/ testimonials.php to read real quotes from published authors. 